\title{
Oriental and Occidental Number Cultures and Their Translation Teaching in English Majors
}

\author{
Tan Zhenghua \\ School of foreign languages, Jianghan University \\ Wuhan, Hubei Province, China \\ 1548297043@qq.com
}

\begin{abstract}
Ethnic culture, religious belief, legends and tales have made a great impact on numbers in eastern and western cultures and they are endowed with special cultural connotation. This paper presents a detailed analysis of number cultures in eastern and western countries. By comparison between Chinese and English numbers in connotation and denotation it focuses on understanding the English and Chinese social cultures and avoiding conflicts and misunderstanding in cultural communication and translation teaching. With the aim to communicate fluently between different cultures, translation criteria of numbers are also discussed. Meanwhile, we draw attention to two differences associated with the use of numbers in different cultures, it can be of great help in translating numerical idioms into English or Chinese.
\end{abstract}

Keywords-number cultures; translation teaching; numerical languages; fuzzy languages; numerical translation

\section{INTRODUCTION}

In mathematics, cardinal numbers, or cardinals for short, are a generalization of the natural numbers used to measure the cardinality (size) of sets. According to Huinan $\mathrm{Bao}(2001)$, the ideas of numbers originates from the nature and were found by people in observing and exploring the world, and Jinzhi Su(1991)explained that, while human beings acclimatized themselves to the demands of social production, with the development of human thinking and the need of human practice numbers in the forms of symbols generated. Numbers belongs to a particular field of linguistics, and functions of numbers applied in science are enumeration, and if the numbers work out problems precisely, orderly and demonstrably, they are real numbers. When the numbers are applied in the field of social psychology, they refer to the semantic meanings. Bingqin Wang(1998) stressed that some numbers had been apotheosized as abstruse, nihilistic, and natural ones which contain connotation and denotation.

People around the world live in different regions and countries, or even an ethnic group different from the others, therefore, the same cardinal number may have a different association meaning in their cultures. Those cardinal numbers take on new symbolic meanings beyond a language. Some Chinese cardinal numbers have the same meaning as them in English even though some are different in the two cultures. The variety in semantic reflect the cultural psychological differences between Chinese and English.

\section{ORIGIN OF NUMBERS AND THE DEVELOPMENT OF COUNTING SYSTEM}

The ancient Indian invented the numeric symbols such as $0 、 1 、 2 、 3 、 4 、 5 、 6 、 7 、 8 、 9$, and then the numbers were passed down to Arabia and from Arabia to Europe. The European thought that the Arabian created those digits by mistake which were called "the Arabic Digits" afterwards. Currently the Arabic numbers are worked in all around the world.

As to the origin of Chinese digits, there are different ideas sharply. Moruo Guo, the historian, literati, poet, and Jiaguwen 1 (inscriptions on bones or tortoise shell) expert argued that the ancient Chinese people conveyed the concept of numbers with their hands and in this way that they found the expressions about numbers. He further pointed out that the idea of numbers are from their hands ,the Chinese characters: 一(one), 二(two), 三(three), 四(four).As follows picture 1 and 2 :

Picture 1

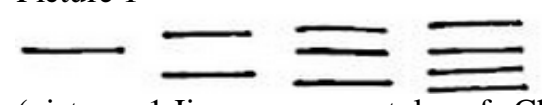

(picture 1,Jiaguwen, a style of Chinese character, produced in about BC 3000, Shang Dynasty)

Picture 2

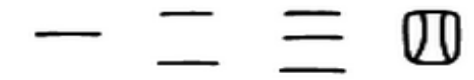

(picture 2, Zhuanti Character, another style, produced in about BC 2500, the Pre-Qin Dynasty which was called the Spring and Autumn Period and the Warring States Period)

The Chinese numeric shapes of 1,2,3,4 are like fingers. But why are the strokes written horizontally? In the ancient China, the Han Chinese ancestors expressed the concepts with their hands . as follows picture 3:

Picture 3

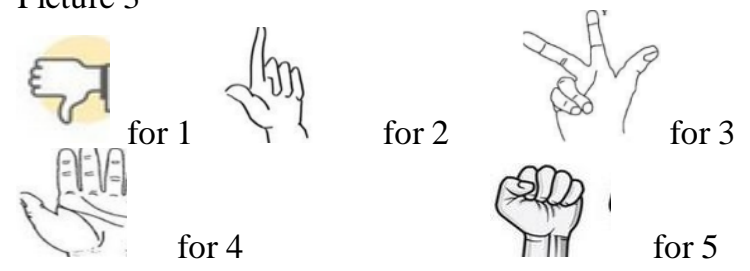

Those pictures show us the numeric meanings horizontally, that is the reason. The Arabic digits were

${ }^{1}$ A style of Chinese character produced in about BC 3000 , Shang dynasty. Characters were written on bones or tortoise shells. 
introduced to China in about 13th century, but they were not adopted .It was not until the 20th century that the Arabic numbers came into use in the cultural field and daily life.

\section{CARDINAL NUMBERS IN CHINESE IDIOMS}

Xinchun $\mathrm{Su}$ (1995) considered that a language is a philosophy and tool with which a people observe the world. National cultural nature is agglomerated in a language. The connotation of a word is a reflection of cultural contents.
Cardinal numbers have been widely used in our life and they get involved in our languages. Numbers are regarded as a special cultural memory stored in every culture. According to the Great Chinese Dictionary 2, compiled by the Chinese Dictionary Committee, there are a large amount of idioms contained numbers from one to nine. The following table is a statistics according to Chinese Idiom Dictionary 3. The total is 15,000 . When cardinal number idioms(1 to 10$)$ are picked out, the data presents as following table 1 :

Table I

\begin{tabular}{|c|c|c|c|c|c|c|c|c|c|c|c|}
\hline idiom & \multicolumn{10}{|c|}{ Cardinal Numbers } & Non- \\
\hline \multirow{2}{*}{$\begin{array}{c}\text { Quantity(in } \\
\text { Chinese idioms) }\end{array}$} & 1 & 2 & 3 & 4 & 5 & 6 & 7 & 8 & 9 & 10 & \multirow{3}{*}{12426} \\
\hline & 1197 & 138 & 358 & 147 & 147 & 82 & 111 & 154 & 107 & 133 & \\
\hline Total & \multicolumn{10}{|c|}{2574} & \\
\hline
\end{tabular}

More numbers, such as 0 , hundred, thousand, 万(10 thousand), 亿 ( 100 million), are not included in the above statistics, the proportion will be larger if all numbers are counted.

Table II

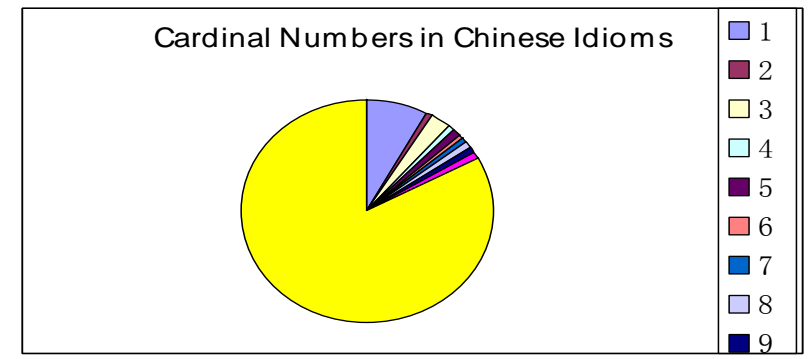

Even members are Chinese preference in all walks of life. The idioms contained number 2,4,6 and 8 are from The Chinese Idiom Dictionary.

IV. SEMANTIC FUZZY IN CARDINAL NUMBERS

The principal function of cardinal numbers is counting. But when they are used in literature or idioms, the meaning of a number is fuzzy. L.A. Zadeh(1965), American scientist, pointed out that the process of human being's aesthesia and thought is fuzzy, and the essence of a descriptive language is vague in the description is usually a summary of complex conditions(D.Dubois, 1980:2). Complexity is in inverse proportion to accuracy. That is, when the matter gets more complicated, it is less likely to analyze or describe accurately. It is not a tragedy when our thoughts can work out the complex problems without the accurate analysis(Paul P.Wang,1980:129). When many words(Chinese characters) defined nowadays definitely are explored the derivation, it would be found that the meanings are vague(Tieping $\mathrm{Wu}, 2000: 337$ ).

${ }^{2}$ Edited by Zufeng Luo, and compiled by the Chinese Dictionary Committee in November ,1986, 22,700 Chinese characters, attached 2000 illustrations, 12 volumes. The first volume was published in 1986, and was completed in November, 1993.

${ }^{3}$ Edited by Xiaoping Xie, 15,000 idioms, in September, 2010,Shanxi People's Education Press, Xi'an.
Precise numbers are not always precise, they are sometimes vaguely used in discourse, which inevitably brings difficulties to translators.

Cardinal numbers used in Chinese are very common, and what they refer to are fuzzy, such as " 1 xin 1 yi(concentration)", "1 qiong 2 bai(very poor)","3 peng 4 you(close friends)", "5 yan 6 se(colorful)", "7 shang 8 xia(very nervous)","9 niu 1 mao(many, much)",etc.

In English, ten, twenty, hundred, thousand, a hundred and one, a thousand and one, million, billion are fuzzy language, too. More examples: times.

(1) He has warned me against pickpocket twenty

(2) I have a thousand and one things to do before we set out for our holiday.

(3) A cat has nine lives.

(4) A stitch in time saves nine.

Expressions like in two twos, two-to-two shop, three-bottle man, third dimension, four square, on all fours, four-lettered words, five-star, five and ten, etc.

\section{A COMPARISON BETWEEN AUSPICIOUS OR OMINOUS NUMBERS}

Pythagoras, the ancient philosopher, mathematician, considered that one, granted by the God, was an impartible entity. One is both a cardinal number and a pronoun. It means "one" and "somebody or something" . "the Holy One" refers to the God, "the Evil One" the Satan, "One and only" the love(lover), "Number One". Han nation sing high praise for one all the time. One symbolizes the beginning ,origin, and ancestor of something and implies "independent, alone", Dingzhang Wang(2009), in Popular Chinese Customs, described that if a girl was engaged, the girl's family would receive a gift-note attached a giving list in details before their marriage. Every gift with a dainty description would come in even number. It is believed that God can be alone, but people cannot. 
In these verses, "один(one)" refers to the God, the spirit.

Two is the first even number in cardinal ones with the meanings of "double", "more" in Chinese. Chinese have the passion for two, and people wish their good lucks, fortunes will come two by two. There are some expressions about two in Chinese, such as "hao shi cheng shuang (Good things come in pairs..)", "shuang xi lin men(Double bliss visit you. )", "liang quan qi wei( to satisfy the both sides)". Many Chinese parents and grandparents name their children with "shuang(two)", or "dui(two)" for the purpose of propitiousness. Meanwhile some idioms contained two are derogatory, such as "er sha zi (fool) ", "er lai zi (hooligan) ", "er bai wu (idiot)" (New Word Dictionary,1993)

But two does not make a good impression on the westerners as it to the orientals. In English, two is an ominous number, and it comes from the plural form "dice" of die, and death isn't welcome. The ancient Romans sacrificed Pluto, King of the Underworld, in February and the dead on the 2nd, February. Since mining digs up wealth from under the earth, Pluto came to be associated with the Underworld, and he became associated with Hades. The name Pluto is more common in Roman mythology, so it is sometimes said that Pluto is the Roman version of the Greek god Hades. Pythagoras also considered that two carried change, disorder. Consequently, it is an odd number(any other but 13) in a bunch of flowers as a giving in the western culture.

Three is one of the Chinese favourite numbers due to its meanings - "many, much" in Chinese culture. Lao tzu 45 , the founder of Taoism, pointed out that the divine law is the beginning (Dao gives birth to one), and one gives birth to two, and two to three, and three to all the things in the universe - from nihil to existence and to infinity. In the changing process three is the key. We always talk about "san yang kai tai (three Yangs make good fortune)", the implied meaning is "All things go well !" and "Good luck!". The quotation spoken in the coming new year is from Changes6, and it conveys the meaning of the next year's beginning. Yang (positive force) is the most powerful material, and the first, second and third trigram of the nine ones are mighty compared to Yin(negative force), therefore the force of three Yangs is beyond compare.

It could be figured out by the structures of Chinese characters that three expresses the primary meanings of “more” such as : “沝(three Chinese characters 水, it means “more water”)”, “森(three 木, more trees, forest )”, “炎(three 火, very hot)”, “晶(three 日, very bright)”, “否(three 石, more stones)”, “众(three 人, more persons, crowd )" .

Pythagoras considered three as a perfect and harmonious number and a changing unity. Three equals trinity , and trinity $=1$ (unity) +2 (diversity), it presents the philosophical development periods(beginning -

Er Li (600 BC. - 470 BC.),Chinese ancient thinker, philosopher, and founder of Taoism in the Spring and Autumn Period.

${ }^{6}$ Chinese ancient classic philosophy works, written in about 3000 BC., Zhou Dynasty. development - end) in a matter. In the early Christian doctrine(tenet), three refers to the Father, the Son, and the Holy Spirit .People who believe the Trinity teaching say that each of these three persons is said to be equal to the others, almighty, and without beginning. The westerners uphold three not only for its sanctity and propitiousness but for its traditional elements, as the world is threefold (earth, sea, and air); man is threefold (body, soul, and spirit); the enemies of man are threefold (the world, the flesh, and the devil); the Christian graces are threefold (Faith, Hope, and Charity); the kingdoms of Nature are threefold(mineral, vegetable, and the animal); the cardinal colors are three in number (red, yellow, and blue)(Brewer's Dictionary of Phrase and Fable, London: Cassell \& Company Ltd. 1963).

There are different ideas about three in British folk customs. It is said that fortune and doom are threefold, two is followed by three, and if the evildoings visit you twice, they will come for a third time. Russians prefers three to the others.

In Changes, Taiji (great supreme) gives birth to Liangyi(two rituals), and Liangyi gives birth to Sixiang ( four directions), so four symbolizes the world. Four also refers to "si fang (the east, north, west, and south)", "the earth(the front, backward, left and right )" But four is not popular with natives in Hongkong, Guangzhou, and Taiwan because of its pronunciation similar to death in Chinese characters. In the south China dialect, the pronunciation of fourteen is similar to “实死(really dead)", people try to avoid to use it.

In Japan , there is no number 4 or 9 clinique or ward. In Japanese, four has the same pronunciation as death[死 (し)], and nine as hardship[苦 $(く)$, surely the patients are inacceptable. 42 is pronounced as “死に(しに)”, correspondingly there is no number 4 park in the park lots or room in the hotels. Some telephone numbers like 4219

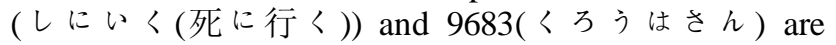
avoided in Japan.

Pythagoras considered four, the first square number, as a perfect number. Four ,thought as "unity", "diligency", and "stabilization", represents missionaries in Christian doctrine, idioms as "the four corners", "the four corners of the earth" , "the four letter word" .

What about five and six ? Five is neither derogatory nor commendatory. It is neutral. People always read "wu gu feng deng(Wish the five cereals (rice, two kinds of millet, wheat and beans) productive.", or "wu fu lin men(May the five fortunes approach our doors.)". wufu refers to "long life", "wealth", "health", "an ethical life", and "a peaceful death". The five principal definitions in the ancient Chinese philosophy are the five elements(Jin, Mu, Shui, Huo, Tu) . Confucians thinks that five is the Golden Mean.Pythagoras took five as a natural and artistic number. The Jesu's scars were five in the Christian doctrine.

Six that has the meanings of "prosperity" and "safety" is also one of the Chinese favourite numbers as two with the same pronunciation of “禄( Chinese character, it means wealth. )" . People prefer 66,666,or 6666 to the other numbers as their telephone numbers or license plate numbers. Pythagoras saw six as justice and the early Christians thought that God created the world in six days. 
as the number In western countries, six is a devil number in the Bible.

In the north China, because of the homophone with “起(it means “rise".)”, seven is popular with the natives. Most Americans are interested in 777 due to the numerical permutation and combination in the gambling slot machines as well as Black Jack(21). In English, seven is holy and mysterious. It has a great influence on the British culture as well as the whole world. God created the world in seven days in the Christian's belief. There are many expressions such as the Seven Sages of Greece, the Seven Bishops, the Seven Virtues, the Seven Deadly Sins, the Seven Gifts of the Spirit, etc.

Eight , in Chinese “八”- apart, which was expressed in Analytical Dictionary of Chinese Characters7, isn't a hieroglyph. People always appoint the date which there is an eight number( the 8th ,18th,28th) as the ceremony day. Eight is similar to the pronunciation of “发

(Chinese character)", and it means "get rich". Most have the passion of choosing an eight number or more eights, if possible, and the more the better, as their house, room, telephone numbers and account number. In the south China, people would spend much money in earning the privilege of "518(I will get rich.)", "918(It will be prosperous.)" "888(to get rich all the time.)" in the business.

In Europe, it is a sign of stability and harmony. According to Bible, eight persons escaped from the Flood, so eight means luck. Jesus's brother, Jacob had 8 children, and the vertical 8 , which looks like two rings, symbolizes a happy marriage. The horizontal 8 “ $\infty$ ”, is an infinite sign which means abundance, longevity, well-being, and posterity. In Matthew, Jesus preached his pupils and talked about the eight events, and eight became the gospel number.

Nine was titled the kings or emperors in ancient China as “九五之尊(imperial throne)”. It is regarded as the largest positive number which symbolizes the powerful force.

\section{SUGGESTIONS TO TRANSLATION TEACHING IN ENGLISH MAJOR STUDENTS}

Cultural accumulations have come from the political events (Watergate scandal, the Gettysburg address, etc.), cultural influence (the ancient Greek mythology). What is culture? It is defined as the totality of beliefs and practices of a society. A language is the carrier of culture, and it is conveyed and communicated through the media of a language. Therefore, to understand the differences between the oriental and occidental cultures is the key to translation teaching.

Suggestions:

Numerical languages reflect a certain culture.

Numerical languages have its vocabulary and is the sign of cultural focus.

Numerical languages are an emotional expression.

Eugene A. Nida, American translator and theorist, thought that : "For truly successful translating, biculturalism is even more important than bilingualism,

\footnotetext{
${ }^{7}$ Edited by Xu Shen, in 100 A.D.- 121 A.D., Chinese Donghan dynasty, one of the most archaic dictionaries, and the first dictionary compiled with Chinese character components in china.
}

only by being in the countries in which a language is spoken can one acquire the necessary sensitivity to the many special meanings of words and phrases." (Eugene A. Nida, 2002:82)

The command of both source language and target language is a must for a qualified translator, but a better understanding of two cultures or more is essential for an excellent translator. Numeric languages are present everywhere and play an important role in our life. Option of auspicious cardinal numbers is human's natural and normal activities and they are only human being' $\mathrm{s}$ wishes for their life. It would be absurd if everything fortunate or unfortunate is associated with numerical numbers. Hengli $\mathrm{Li}$, chairman of the International Taoism Fund, claimed that there is no necessary consequence between numerical numbers and fortune. The association meanings of the digital numbers are an emotional expression and experience to the real society.

\section{ACKNOWLEDGMENT}

I would like to express my heartfelt gratitude to Prof. Wu Lifang, school of French, Prof. Li Deyu, school of Japanese for their advice and support.

This paper is one of researches of 2015 Teaching and Research Project for Wuhan Municipal Universities entitled the Application of English Corpus-based Translation Teaching in English Majors of Chinese Universities.

\section{REFERENCES}

[1] Baoqing HU. Fuzzy Theory. Wuhan. Wuhan University Press, 2010.

[2] Dingzhang Wang. Popular Chinese Customs.Sichuan People's Press.Chengdu. 2009.

[3] Bingqin Wang. On Language and Translation. Tianjin: Nankai University Press. 1998.

[4] Jinzhi Su. Numerical Totem. Language Press, Beijing, 1991.

[5] Hongqi Wang. Mysterious Numbers in the Real World. China Translation \& Publishing Corporation. Beijing. 2003.

[6] Jianzhong Guo. Culture and Translation. China Translation \& Publishing Corporation. Beijing, 2003.

[7] Zhengxu Xu. Pythagoras. Huangshan Press. Hefei. 2010.

[8] Brewer's Dictionary of Phrase and Fable. London: Cassell \& Company Ltd.. 1963.

[9] D.Dubois,H.Prade..Fuzzy Sets and Systems-Theory and Applications. Newyork: Academic Press. 1980

[10] Deiser, Oliver . On the Development of the Notion of a Cardinal Number. History and Philosophy of Logic 31 (2), 2010 ,123-143.

[11] Huinan Bao. Cultural Context and Language Translation, China Translation \& Publishing Corporation. Beijing, 2004.

[12] Jie Rong. Numbers, A Special Memory. Chinese Russian Teaching(3), $2003,: 47-52$.

[13] Paul P.Wang, Fuzzy Sets-Theory and Applications to Policy Analysis and Information Systems. Plenum Press, Newyork, 1980.

[14] Tieping Wu, Fuzzy language.Beijing Normal University Press. Beijing. 2000.

[15] Tieping Wu. Fuzzy Language. Shanghai Foreign Language Education Press, Shanghai, 2000.

[16] Xianwen Xu. On Cultural Semantics of Cardinal Numbers in English and Chinese.Journal of Heilongjiang University, (6):107111. 2005.

[17] Xiaoping Xie. Chinese Idiom Dictionary. Shanxi People's Education Press. Xi'an. 2010.

[18] Xinchun Su. Chinese Modern Lexicology. Guangdong Education Press. Guangzhou. 1995. 
[19] Zaixi Tan. A Review of Nida's Theory on Translation. China Translation \& Publishing Corporation. Beijing, 2003.

[20] Zhengsheng Cai. Comparison Between Chinese and Japanese Cultures. Beijing Foreign Studies University Press. Beijing. 1995.

[21] Eugene A. Nida. Language and Culture. Foreign Language Education Press, Shanghai. 2002.
[22] Zhizhong Li. Derogotary idioms contained number 2. Journal of Xinjiang University, (3):83-87. 2007.

[23] Zufeng Luo. Great Chinese Dictionary .Chinese Dictionary Press. Beijing. 1993. 